NAMAN GUPTA

62 'A' Pathani Tola Biswan

Sitapur Uttar Pradesh India

(261201)

ngstudies.tk@gmail.com

8604988103, 7007298010
CHHAVI VISHNOI

Indra Colony, Katghar

Moradabad Uttar Pradesh

India (244001)

vishnoichhavi@gmail.com

9536240277
ZAMIN AHMED

Barabari Mehmoob

Khan, Near Keley Masjid

Rampur, UP India

ansarizamin.78699@gmail.com

7452001357

\title{
Contactless Thermal Detection System
}

$10^{\text {th }}$ September 2020

\section{OVERVIEW}

In this COVID-19 pandemic situation as we know Offices are partially opened and Schools and Colleges are about to open. So we have to face the situation with the possible measures to reduce the spreading of the COVID19. We have to move on by implementing strong protective measures while trying to keep the economy going.

According to WHO Some of most common ways to protect ourselves from COVID19 are as follows:

- Take care in your workplaces.

- Take care of physical distancing.

- Take care to spread the word not the virus.

- What to consider for health before opening the workplace

- Take care of sanitisation

- Take care of yourself.

In these most common and preferable ways to protect ourselves is Proper Screening and if something went wrong in this then proper precautions.

So while the time of screening the one who is checking the temperature of everyone can be more in danger, and this can also lead to more spread of virus. Because if while screening someone who is Positive, the one who is screening the positive patient can also get affected and after that he can affect more people by just screening them.

So at this time we need to find the alternative for screening everyone contactlessly. For this we came up with a solution that is Contactless Thermal Detection which is made with all the safety measures for the Organisation or any public places where we 
screening for temperature is needed for Covid. With this Employees, Workers, Students, Teachers can record their temperature while entering their respective workplaces contactlessly.

\section{GOALS}

With this we aim some points which are given below:

1. Contactless Temperature Detection.

2. Low cost and easy to install.

3. Ease to use for even playgroup students or illiterate workers.

4. Automatic Height Adjustable Thermal Sensors.

5. Proper Database record of everyone.

6. Face recognition and auto storing the pre saved faces.

7. New record for guest employees or visitors.

8. Energy Efficient, The device will be active only when someone passes through.

9. Time saving

10. Device will let someone enter by the gate only if his temperature will be below the covid standards and will inform this to respected authorities.

\section{SPECIFICATIONS}

The proposed device will be structured just like a metal detector in shopping malls and will have one Thermal Detection sensor which will be automatically height adjustable according to the person passing through the machine. Device will have one barricade which will only be open if someone has the temperature between the standards of COVID 19 Novel CoronaVirus. With this device will also be storing the temperature and photo of everyone passing through and if the photo will be already in record then the temperature will be added to previous record of if device doesn't have the face earlier saved then that face will be added to the device.

So with this the device will be totally automatic and there will be no need to touch the device and there will be less chances of spreading of the virus while screening. 


\section{WORKING}

The device will be divided into modules which are given below:

1. Temperature Detection Module

2. Automatic Height Adjustment Module

3. Face Detection and Data Saving

4. Barricade Module

All the four modules will combine and make a whole device which will be able to Contactlessly Measure the Temperature and store it to records.

The combine working will be as follows:

1. Before entering the office or school or some other place firstly one have to pass through the device just like metal detectors at malls.

2. When someone will come closer to the device the device will get active automatically with the help of sensors.

3. Now the camera will click the picture and will match the picture into the database.

4. If the picture will be already in the database then step 6 else step 5 .

5. If the picture will not be in the database then new record with the picture will be updated.

6. Now the device will adjust the height of the thermal sensor placed in the device according to the height of the person detected automatically.

7. Now the sensor will record the temperature and update it to the records.

8. If the temperature of the person is according to the standards then the barricade will be open.

9. If temperature is not according to the standards then the alarm will be pinged to the respected authorities.

10. Same process will be followed every time when someone will be detected by the device. 


\title{
CONTACTLESS THERMAL DETECTION PROCESS
}

\author{
WHEN SOMEONE WILL BE DETECTED
}
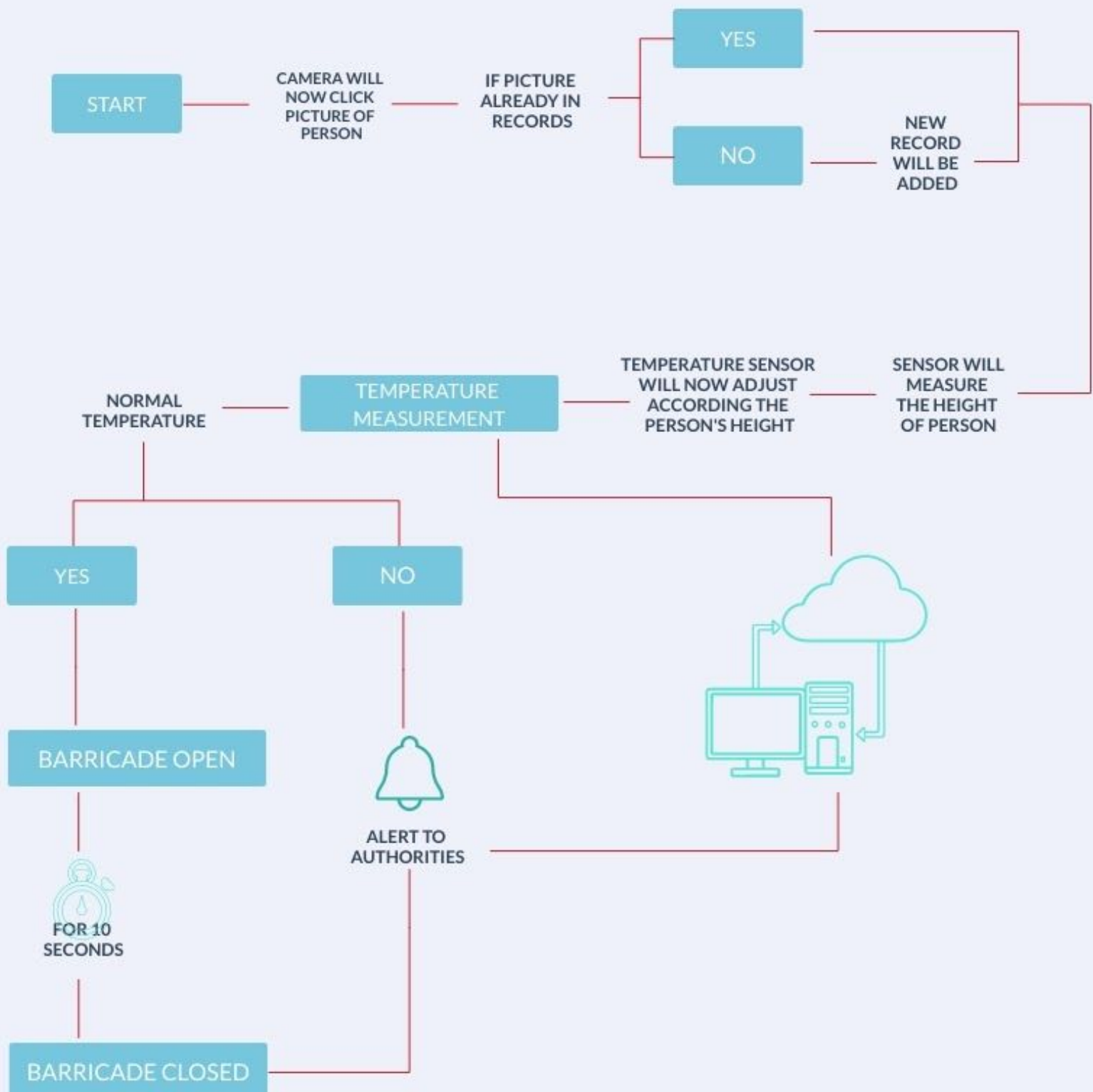


\section{MODULES DESCRIPTION:}

As mentioned above the whole device will be divided into many modules each module has its specific task.

The device will be divided into modules which are given below:

* Temperature Detection Module

* Automatic Height Adjustment Module

* Face Detection and Data Saving

* Barricade Module

Temperature Detection Module: Temperature Detection Module is the main part of the whole device which is responsible for the detection of Temperature. In this module sensors which are used are:

1. MLX90614ESF MLX90614

2. NODEMCU ESP8266

MLX90614ESF MLX90614: The MLX90614ESF is used as Contactless Digital (IR) Temperature Sensor. This sensor can be used to measure the temperature of a particular object ranging from $-70^{\circ} \mathrm{C}$ to $382.2^{\circ} \mathrm{C}$. The sensor uses IR Rays to measure the temperature on the object without any physical contact. This communicates with a microcontroller using the I2C Protocol.

\section{MLX90614 Temperature Sensor Specifications}

- Operating Voltage: $3.6 \mathrm{~V}$ to $5 \mathrm{~V}$ (available in $3 \mathrm{~V}$ and $5 \mathrm{~V}$ version)

- Supply Current: $1.5 \mathrm{~mA}$

- Object Temperature Range: $-70^{\circ} \mathrm{C}$ to $382.2^{\circ} \mathrm{C}$

- Ambient Temperature Range: $-40^{\circ} \mathrm{C}$ to $125^{\circ} \mathrm{C}$

- Accuracy: $0.02^{\circ} \mathrm{C}$

- Field of View: $80^{\circ}$

- Distance between object and sensor: $20 \mathrm{~cm}$ (approx.) 
NODEMCU ESP8266: NodeMCU is an open-source Lua based firmware and development board specially targeted for loT based Applications. It includes firmware that runs on the ESP8266 Wi-Fi SoC from Espressif Systems, and hardware which is based on the ESP-12 module.

\section{NodeMCU ESP8266 Specifications \& Features}

- Microcontroller: Tensilica 32-bit RISC CPU Xtensa LX106

- Operating Voltage: $3.3 \mathrm{~V}$

- Input Voltage: 7-12V

- Digital I/O Pins (DIO): 16

- Analog Input Pins (ADC): 1

- UARTs: 1

- SPIs: 1

- I2Cs: 1

- Flash Memory: $4 \mathrm{MB}$

- SRAM: 64 KB

- Clock Speed: $80 \mathrm{MHz}$

Automatic Height Adjustment Module: Height Adjustment module is that part of the device by which device will automatically set it's height according to the person who will be passing through the device.

We need this module because as we know in COVID19 scenario we have to measure the temperature of the head and as every person has a different height so for this it's necessary to set the temperature detection module in front of the forehead.

In this module we are going to use HCSR-04, Geared Motor \& Relay Module-5W. Basically HCSR-04 is also known as ultrasonic sensor.

\section{HC-SR04 Sensor Features}

- Operating voltage: $+5 \mathrm{~V}$

- Theoretical Measuring Distance: $2 \mathrm{~cm}$ to $450 \mathrm{~cm}$

- Practical Measuring Distance: $2 \mathrm{~cm}$ to $80 \mathrm{~cm}$

- Accuracy: $3 \mathrm{~mm}$ 


\section{Features of 5-Pin 5V Relay}

- Trigger Voltage (Voltage across coil) : 5V DC

- Trigger Current (Nominal current) : 70mA

- Maximum AC load current: 10A @ 250/125V AC

- Maximum DC load current: 10A @ 30/28V DC

- Compact 5-pin configuration with plastic moulding

- Operating time: $10 \mathrm{msec}$ Release time: $5 \mathrm{msec}$

- Maximum switching: 300 operating/minute (mechanically)

Face Detection and Data Saving: The face detection and data saving module will be responsible for the auto detection of face and storing the data in records accordingly, the module will also be capable of storing new faces within the database.

For this we are going to use python with open $\mathrm{cv}$ for face detection and camera module for capturing the face. This module will be trained with some pre stored face records.

After that the received temperature will be saved to the database connected with software made in with the python.

Barricade Module: This part of the module will be activated after the successful checkup and confirmation of valid temperature according to the covid standards.

In this module if the person will be having the valid temperature according to the covid standards then the barricade will be opened else the person will be reported to the respective authorities.

For this module we are using Servo Motor SG-90.

\section{SG-90 Features:}

- Operating Voltage is $+5 \mathrm{~V}$ typically

- Torque: $2.5 \mathrm{~kg} / \mathrm{cm}$

- Operating speed is $0.1 \mathrm{~s} / 60^{\circ}$

- Gear Type: Plastic

- Rotation : $0^{\circ}-180^{\circ}$ 


\section{MODULES WORKING:}

All the modules will be internally connected with some microcontrollers like arduino uno, raspberry pi, esp8266 or anyone compatible. These microcontrollers will be handling the working part of the device and the device will be directly connected with the NODEMCU ESP8266 module which will be connected with the database server directly for communication with the database.

Firstly when a person will come near the device the device will get active and the camera module will be activated, at the same time HCSR04 will measure the height of the person by emitting the ultrasonic rays. Then the calculated height will be sent to the height adjustment unit of the device which will set the height of the temperature detection module connected with the geared motor. After setting up the height the temperature sensor will be activated and it will measure the temperature and send it to the nodemcu nodemcu will check the temperature and send it to the database and send signal to the barricade module according the temperature if temperature will be ok then the barricade will be opened otherwise the barricade module will trigger alarm to the respected authorities by sending signal to the server.

All the modules in the device have their own working part which makes the device easy to maintain and while in condition on any failure the device will be easy to repair.

Device is designed keeping various conditions in mind which are as follows:

1. Persons of various heights.

2. Person's image not in database.

3. Person having higher temperature than covid standard.

4. When Someone is leaving through the same gate.

5. In case of emergency.

6. Inbuilt Hand Sanitizing system.

7. Time factor.

8. Contactless tracking.

9. Contactless temperature measurement.

10 . No need to touch any device total automatic working.

11. No manpower needed. 
Device working has been shown in below given pictures:

Here you can see the camera process,

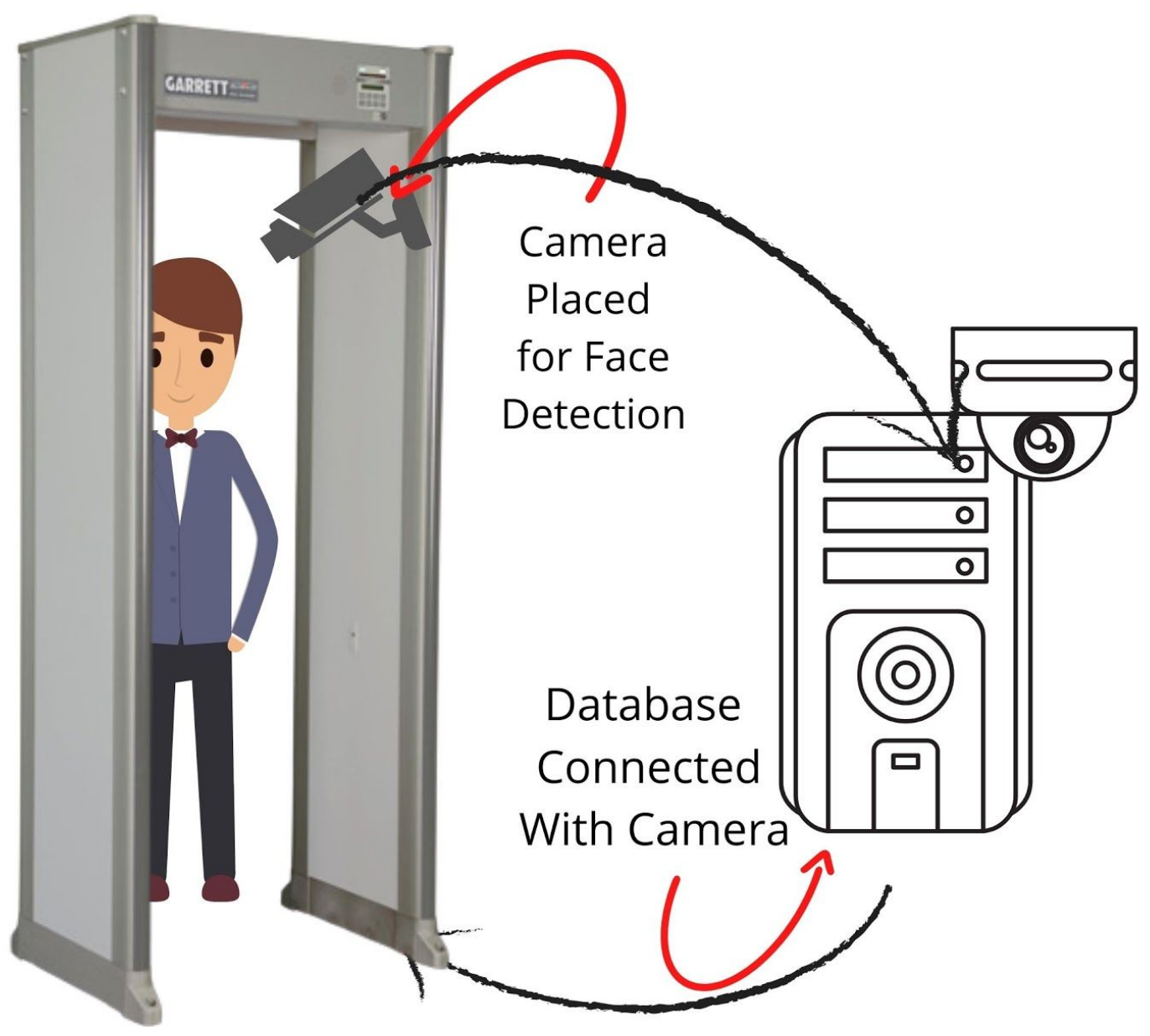

In the above picture as you can see when a person comes in front of the device camera clicks the picture and checks if the picture matches the person already saved in the database. If a person is not in record then it will create a new record with that person's image. 


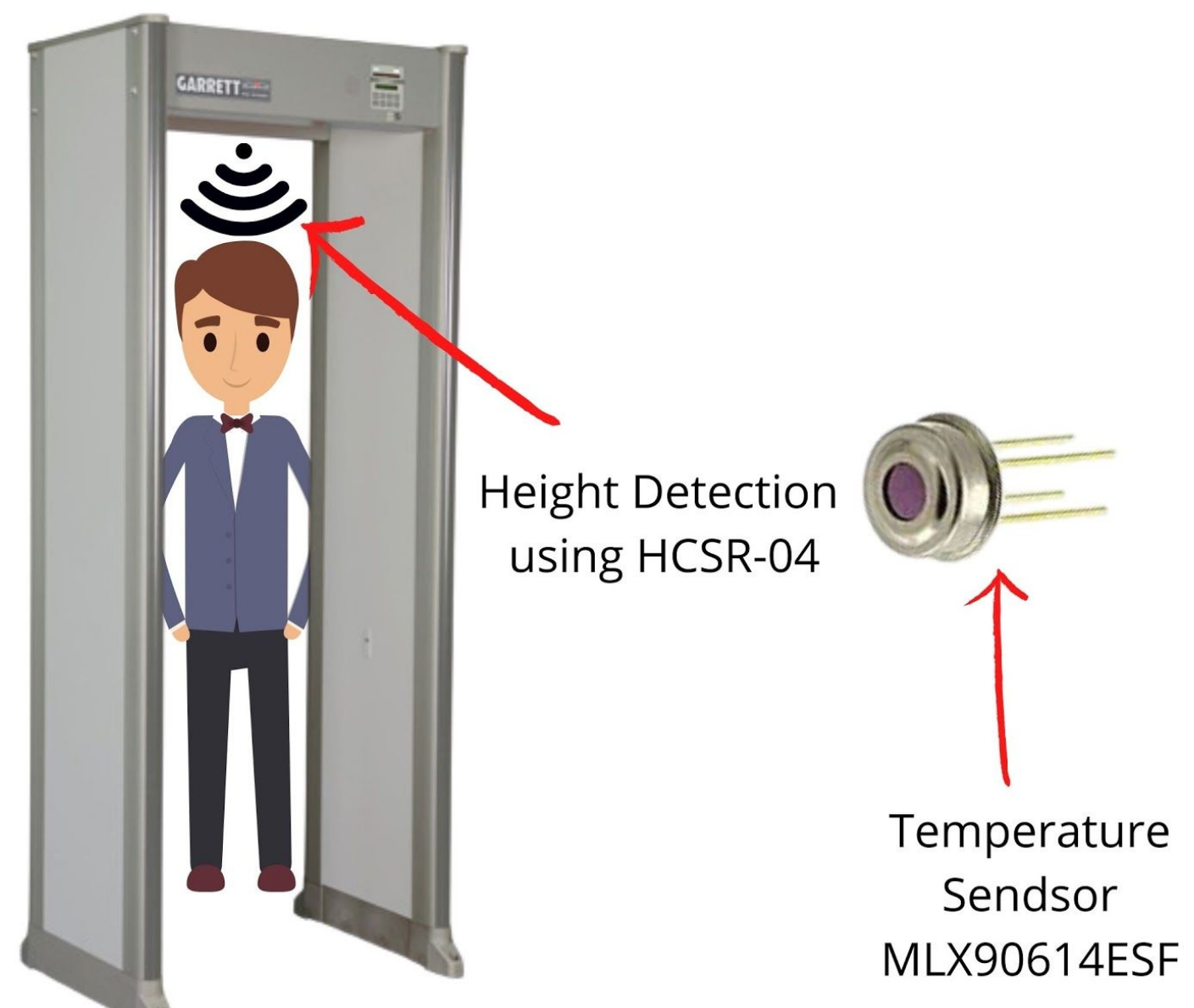

HEIGHT DETECTION USING HCSR-04 ULTRASONIC SENSOR

In the above picture you can see the ultrasonic sensor measuring the height of the person. The ultrasonic sensor emits the ultrasonic rays and gets those back on it and calculates the height of the person with it.

The above picture also shows the temperature sensor MLX90614ESF. Which has been used in the device for temperature measurement. 
In these below given three pictures you can see the temperature sensor location for various heights:
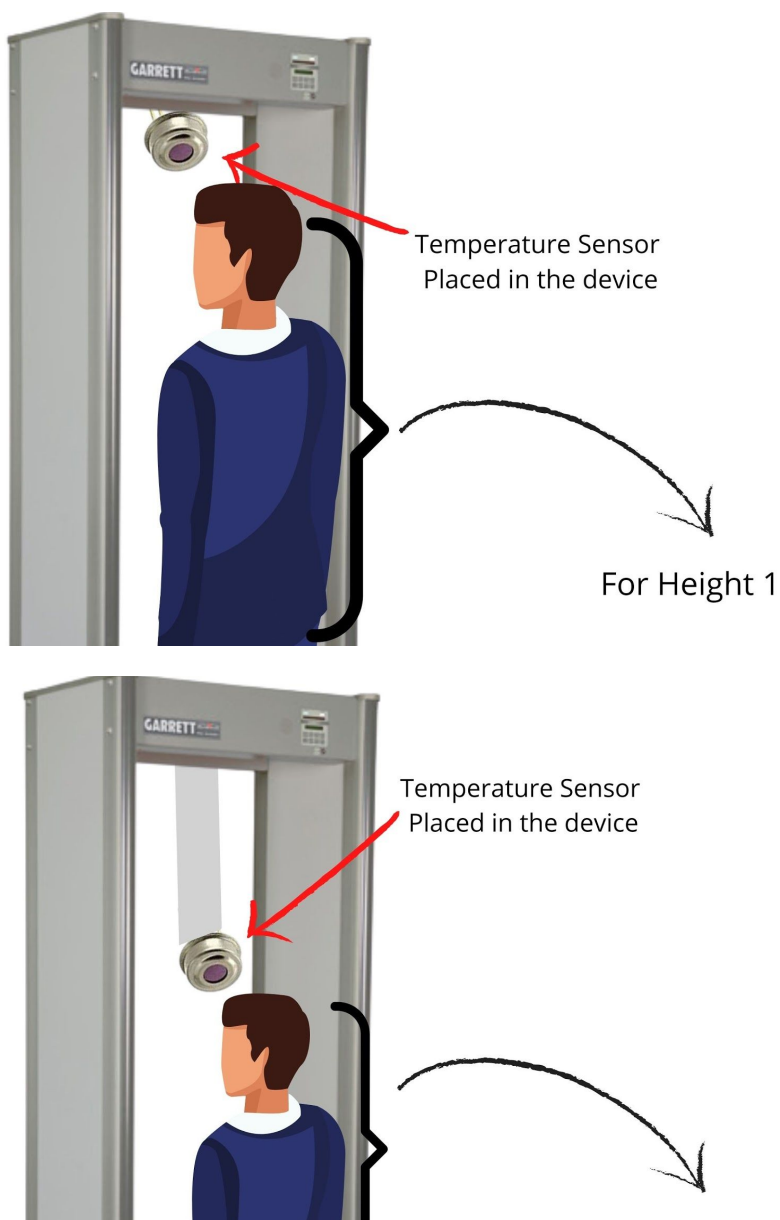

For Height 2

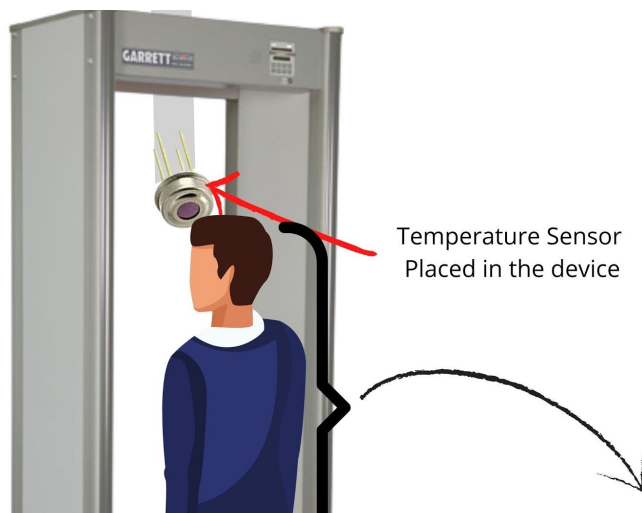

For Height 3 


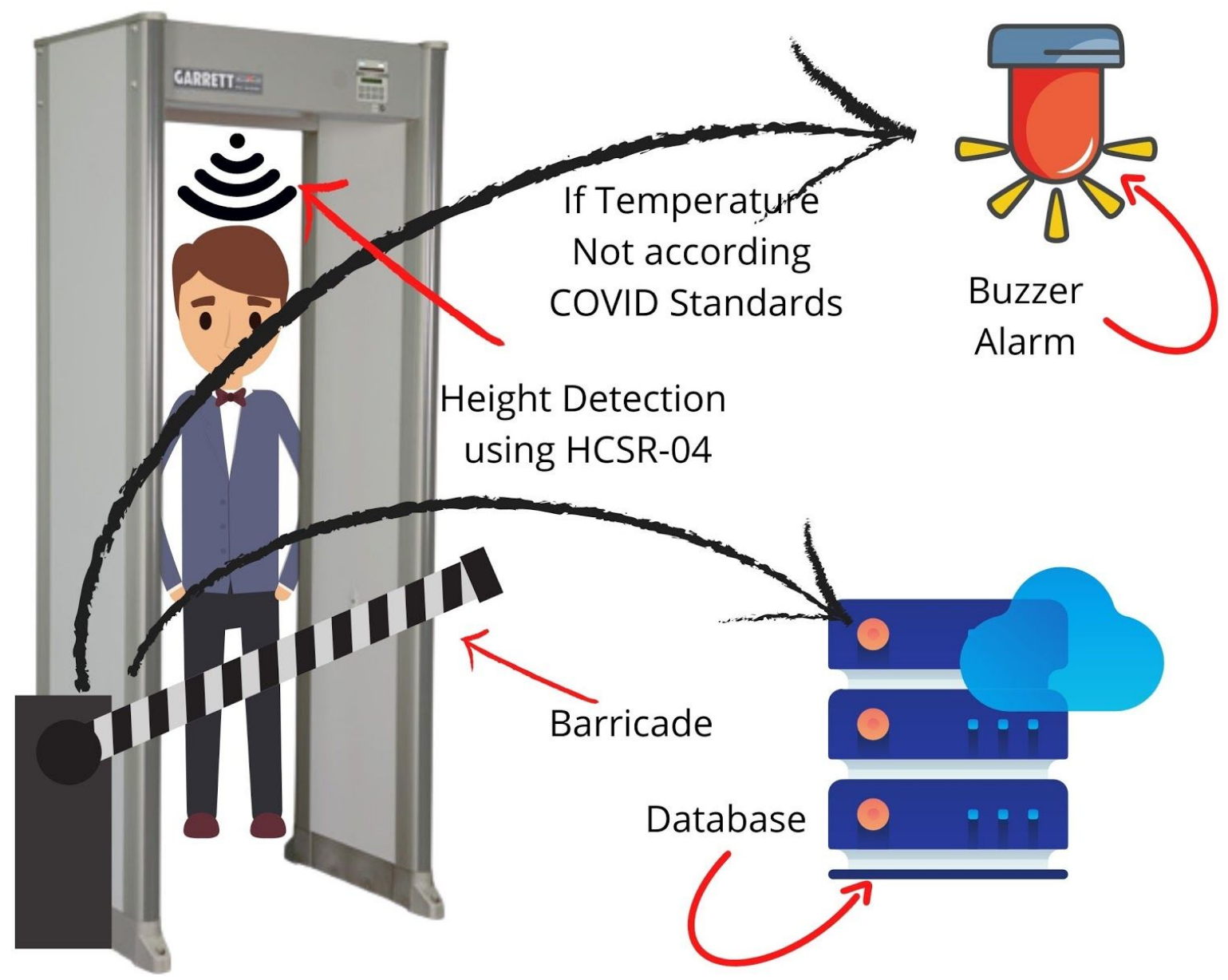

In this image you can see the barricading module, as you can see it is connected with the database so it will automatically activate according to the temperature of the person and save the logs of opening in the database and it will also alert the authorities if someone is found with the above temperature than covid standards.

\section{GOALS ACHIEVEMENT:}

With the device we are achieving all the goals mentioned above.

a. Contactless Temperature Detection: With the help of device no one will get in contact with anyone while checking the temperature as device is totally automatic here is no need of anyone to let operate the device.

b. Low cost and easy to install: As devices are divided into many modules so it is easy to install in any large sized or small sized organization. With this it is using very cheap sensors which make it low cost. 
c. Ease to use for even playgroup students or illiterate workers: It's fully automated feature makes it easy to use, that's why a person with zero technical knowledge or even a child can easily go through this.

d. Automatic Height Adjustable Thermal Sensors: It's automatic height adjustable thermal sensors make it useful for all aged or all sized people. As we know if we see practically everyone doesn't have the same height so in that case user has to adjust their height by themselves if the device is not automatic height adjustable so we have made it automatic height adjustable which makes it more effective and non contact.

e. Proper Database record of everyone: Device keeps record of each and every person passing through it. For this we have some pre recorded faces. If the device doesn't have that record then it creates the one automatically and adds the entry of that person properly in database.

f. Energy Efficient: Device is energy efficient as we have implemented the device in such a way that if the device is not in use then it will not consume a single watt of electricity. That makes it energy efficient.

\section{CONCLUSION:}

In this COVID-19 pandemic situation as we know Offices are partially opened and Schools and Colleges are about to open. So we have to face the situation with the possible measures to reduce the spreading of the COVID19. We have to move on by implementing strong protective measures while trying to keep the economy going.

So for this we need to be more attentive as the cases are increasing day by day. So in that case the device is very effective. As the device is configured keeping every age person in mind so it will be helpful and efficient for everyone. 
(20) 